\title{
O que deve ser feito para melhorar as
} Norman Gau* escolas paulistas?

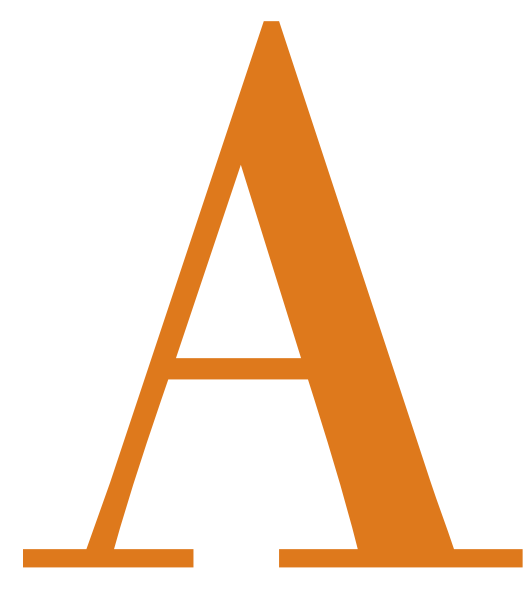

TV Globo, na sua novela Os Sete Pecados, mostra uma escola pública na periferia de São Paulo. A escola está coberta de grafites, ensina pouco e funciona sob ameaça permanente de desordem. Uma jovem diretora idealista chega a essa escola prometendo melhorar o ensino e o aprendizado, mas desiste depois de uma guerra de comida na cantina da escola. Ela decide renunciar, porém um aluno pobre a convence a ficar, suplicando: "A senhora precisa ficar, é a única pessoa aqui que se preocupa com a gente, de outro jeito nunca vou aprender nada nessa escola."

Nos registros sobre a educação pública não faltam exemplos de heroísmo individual - de diretores, professores e estudantes - lutando contra a esterilidade e 0 desperdício de um sistema fracassado. Mas o desempenho do sistema como um todo - ou dos sistemas, nessa federação descentralizada de Estados e municípios - é tão ruim que, no geral, está corroendo a estabilidade e o desenvolvimento futuro do Brasil.

Os apelos para que se inicie uma reforma séria são ouvidos cada vez com mais intensidade. As reformas da educação pública normalmente começam sob condições adversas. Seu sucesso depende da liderança política no topo das instituições públicas e também da mobilização no ponto mais baixo da pirâmide social que se beneficiaria com escolas melhores.

* Norman Gallé diretor executivo do Instituto Fernand Braudel de Economia Mundial <www.braudel.org.br 〉, e-mail: 〈ngall@braudel.org.br 〉. 
O governo do presidente Luiz Inácio Lula da Silva estabeleceu um prazo para as escolas brasileiras atingirem os níveis de desempenho médio encontrados nos países mais avançados: 2022. Que políticas e investimentos novos são necessários para que o Brasil se aproxime da meta?

\section{Desenvolvimento da capacidade institucional}

\section{No início deste ano, e durante cinco semanas, uma equi-} pe do Instituto Fernand Braudel de Economia Mundial realizou uma pesquisa de campo sobre a reforma escolar em Nova York, entrevistando estudantes, professores e diretores em escolas de bairros pobres, para saber que estratégias e métodos poderiam ser utilizados para melhorar a educação pública em São Paulo e no Brasil. A principal lição desse trabalho é que o País precisa investir no desenvolvimento da capacidade institucional.

Descobrimos que as reformas realizadas em Nova York seguiram um modelo desenvolvido na Inglaterra nas duas últimas décadas, instituído no governo conservador de Margaret Thatcher e consolidado na última década pelo governo trabalhista de Tony Blair.

Segundo Michael Barber, que conduziu a reforma escolar na Inglaterra de 1997 a 2005, as "reformas realmente radicais" da era Thatcher-Blair progrediram com base em três idéias centrais:

1. a criação de padrões e responsabilidade;

2.a criação de capacidades e colaboração, "garantindo a oferta de professores e melhorando seus salários, criando oportunidades para as escolas colaborarem, e investindo no desenvolvimento profissional";

3.a formação de um "quase-mercado em serviços públicos, explorando o poder de escolha, a competição saudável, a transparência e os incentivos, e é nesse campo que o debate educacional está entrando agora".

As condições adversas em São Paulo e Nova York têm sido o desempenho acadêmico precário, os altos índices de evasão escolar, a ausência de um padrão de ensino, a desordem crônica nas escolas, a falta de uma supervisão eficaz, o desânimo e a apatia entre os professores e as poucas expectativas de um futuro melhor.

No caso de São Paulo, a essas dificuldades deve-se acrescentar a proteção legal para as faltas freqüentes de muitos professores, o que agrava a desordem nas escolas e desmoraliza os alunos, e também a negligência e a anarquia dos currículos e métodos de ensino que contribuem para as altas taxas de fracasso acadêmico. Além disso, a classe política do Brasil não tem muito interesse em promover os esforços a longo prazo para melhorar o ensino e o aprendizado.

Em Nova York, o grupo que liderou a reforma escolar surgiu fora da classe política tradicional, conduzido pelo prefeito Michael Bloomberg, um empresário bilionário, e o secretário da Educação Joel Klein, advogado.

Da mesma maneira, os líderes empresariais brasileiros começaram a fazer pressão em favor de melhorias no ensino público. Esses esforços precisam ser intensificados e expandidos para ganharem impulso.

O Brasil tem algumas vantagens para melhorar suas escolas:

1. seu sistema federativo descentralizado abrange uma ampla variedade de Estados e municípios de diferentes tamanhos e perfis econômicos e sociais. Essa diversidade serve para experimentos com diferentes abordagens e estratégias locais;

2.refletindo a preocupação generalizada sobre a qualidade do ensino público, o Governo Federal lançou recentemente o Plano de Desenvolvimento Educacional (PDE), prometendo um grande financiamento nos próximos anos;

3.o jovem ministro da Educação, Fernando Haddad, desfruta da confiança do presidente Lula e das lideranças educacionais;

4.05 esforços para melhorar as escolas públicas contam com apoio político e financeiro do setor privado. O Ministério da Educação adotou as metas propostas no plano "Todos pela Educação", uma coalizão do setor privado;

5.o Estado de São Paulo, com uma população maior do que a da Argentina ou da Califórnia (41 milhões) e com um dos maiores sistemas escolares do mundo (5,5 milhões de alunos) está em excelente situação fiscal para financiar a melhoria do ensino público. Contará com impostos e royalties adicionais vindos da atividade econômica gerada pelas recentes descobertas de gás e petróleo na Bacia de Santos.

Mais denúncias e diagnósticos do que soluções

Apesar das críticas sobre a falência das escolas brasileiras, algumas iniciativas importantes vêm surgindo. 


\section{No momento, o \\ sistema escolar \\ brasileiro carece de \\ uma capacidade \\ institucional que \\ promova um \\ aperfeicoamento \\ do ensino e do \\ aprendizado.}

O Distrito Federal, com um sistema escolar que abrange 500 mil alunos, está adotando um currículo unificado e incentivos para o desempenho de escolas e professores, como parte das negociações salariais, e está implementando um dos primeiros programas de segurança escolar no Brasil.

Em Minas Gerais, onde, a partir de 1991, as reformas no sistema educacional foram esporádicas, a eleição, pela comunidade, dos diretores de escolas aprovados em exames de qualificação se consolidou. Encontrouse um meio para se demitir os professores deficientes. E, mais importante, o nível de alfabetização dos alunos é testado depois dos seus dois primeiros anos na escola primária, para reforçar a aprendizagem.

Em Pernambuco, o programa Procentro, patrocinado pelo setor privado, oferece um ensino secundário de alta qualidade e em tempo integral em escolas públicas de 20 cidades do interior.

É mais fácil denunciar e diagnosticar as deficiências do ensino público brasileiro do que propor soluções viáveis.

Como o Brasil é um vasto arquipélago de diversas comunidades, com diferentes níveis de desenvolvimento, o seu sistema federal descentralizado desencoraja iniciativas no campo educacional que possam abranger a nação inteira.

Os investimentos precisam ser seletivos, baseados em iniciativas de estados e municípios que tentam melhorar as escolas locais e buscam apoio financeiro e técnico.

Esforços localizados e dispersos podem ser importantes, embora qualquer empenho significativo para melhorar as escolas do Brasil levará anos e exigirá uma estratégia a longo prazo coerente para superar estas dificuldades básicas:

\section{O que ensinar?}

É preciso um conteúdo maior e melhor. Uma razão para que as crianças brasileiras aprendam tão pouco na escola e apresentem um desempenho tão medíocre nos testes nacionais e internacionais é que não existe nenhum currículo adotado pelas autoridades municipais, estaduais ou federais. Os vagos "parâmetros curriculares" do Ministério da Educação orientam muito pouco os professores quanto aos conteúdos na sala de aula. É necessário um esforço dedicado para se adotarem padrões de aprendizagem e um currículo mais enriquecido.

\section{Implementação das mudanças}

Devem ser criados novos institutos, similares à Leadership Academy de Nova York, a fim de treinar supervisores, mentores e mestres a intervirem nas salas de aula para darem um suporte às melhorias na prática do ensino. No momento, o sistema escolar brasileiro carece de uma capacidade institucional que promova um aperfeiçoamento do ensino e do aprendizado.

Não existe supervisão ou apoio algum aos professores no trato de suas próprias deficiências e do fracasso de um aluno no seu aprendizado. Entre as burocracias centrais e as escolas e professores não há gestores intermediários para implementar os padrões e as práticas.

As novas metas anunciadas pelo Governo Federal e propostas por grupos privados não serão alcançadas sem que se promova esta gestão intermediária e a qualidade da supervisão. Para isso, são necessários investimentos. E, no caso da supervisão, ela é especialmente importante porque as universidades e institutos de pedagogia preparam mal os professores para o trabalho em sala de aula.

\section{Novos incentivos}

Para melhorar o ensino público, é preciso uma reestruturação dos incentivos.

Professores, diretores, escolas inteiras e distritos escolares precisam de recompensas pelo melhor desempenho dos alunos. Ausências freqüentes de professores e diretores não devem ser toleradas. 


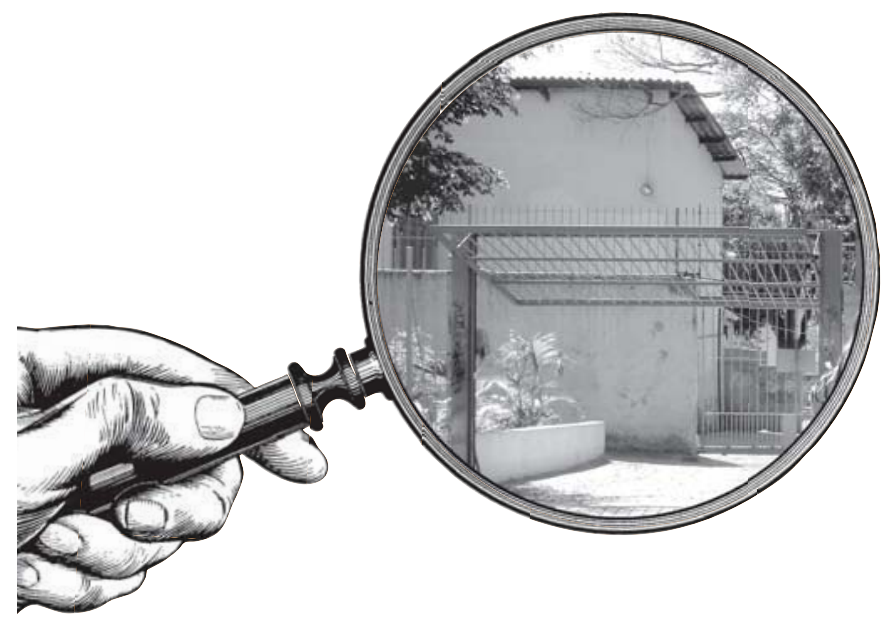

Avaliação do progresso

Os dados produzidos pelos exames estaduais e nacionais não são usados para diagnosticar e melhorar o desempenho do estudante. Em muitos casos, nem chegam às escolas. Escandalosamente, os resultados dos testes promovidos pelo Sistema de Avaliação de Rendimento Escolar do Estado de São Paulo - Saresp não são nem mesmo publicados. Assim, os pais ficam desprovidos de informações vitais sobre o progresso acadêmico de seus filhos e suas escolas.

O Ministério da Educação promete corrigir essa faIha, dando notas a todas as escolas do Brasil, como está sendo feito em Nova York. Mas é preciso melhorar a avaliação, com conseqüências não só para um desempenho excelente como também para o medíocre.

As escolas devem fazer anualmente uma auto-avaliação e, junto com suas comunidades, estabelecer um plano de ação para melhorar seu desempenho nos testes padronizados.

A cada três anos, devem ser realizadas avaliações de qualidade por profissionais visitantes.

As autoridades brasileiras também devem considerar a criação de uma superintendência autônoma para avaliar o desempenho escolar, no estilo da instalada recentemente no Chile.

\section{As regiões metropolitanas}

Entre as 14 cidades brasileiras com população de mais de 41 milhões de habitantes, o gigantesco sistema escolar de São Paulo exibe as maiores dificuldades das áreas metropolitanas. Nos exames do Saresp, os alunos freqüentemente são questionados sobre temas que nunca lhes foram ensinados em sala de aula.

A Fundação Sistema Estadual de Análise de Dados - Sead está elaborando os perfis de todas as 5.800 escolas do Estado de São Paulo, como matrículas, rotação de professores, resultados de testes, promoções, índices de evasão escolar e condições socioeconômicas. Com esses dados, que se acumularam na Secretaria da Educação Estadual sem utilização durante anos, as autoridades poderão direcionar suas intervenções baseando-se nas necessidades de cada escola.

Os governos estaduais anteriores tiverem pouco interesse na solução de problemas sistêmicos da educação pública. Até recentemente havia pouca pressão popular para uma melhora da qualidade do ensino e uma indiferença geral da classe política.

O sistema não entrou em colapso por causa da demanda pública por algum tipo de ensino e porque as escolas são uma fonte abundante de emprego formal e aposentadoria para professores e administradores que, em troca, propiciam um grande número de votos para as elites políticas.

O sistema, em grande parte, é governado por incentivos perversos, que são as regras legais e os costumes de premiar comportamentos contrários aos objetivos declarados das instituições. O sistema não se importa com resultados e parece funcionar visando mais ao benefício de seus empregados e menos ao das pessoas que devem servir.

Em Nova York, o lema da reforma do ensino é "Primeiro, as Crianças". Não vemos esta prioridade em São Paulo.

É preciso investir mais recursos no processo de aprendizagem. Isso implica criar um currículo básico que estabeleça metas claras para o ensino. Significa a mudança de leis e regulamentos para reduzir as ausências dos professores, um grande problema do sistema educacional brasileiro desde o século XIX. Implica ainda o treinamento de supervisores e mentores para trabalharem dentro das salas de aula com professores e alunos, com o objetivo de melhorar os resultados. 


\author{
É preciso investir \\ mais recursos \\ no processo de \\ aprendizagem. Isso \\ implica criar um \\ currículo básico que \\ estabeleca metas \\ claras para o ensino.
}

Significa também descentralizar os poderes de decisão, dentro de uma estrutura geral, para uma direção regional e os diretores de escolas que, em troca, vão se responsabilizar pelos resultados.

$\mathrm{O}$ sistema precisa investir na liderança regional. Em algumas regiões, devem ser desenvolvidos programaspiloto, como ocorreu no Bronx, onde novas estratégias e métodos foram experimentados antes de serem aplicados em toda a cidade de Nova York.

Os planos de estudos e os métodos de ensino devem ser enriquecidos para os 700 mil estudantes secundários de São Paulo, obrigados a estudar à noite, assistindo a aulas estéreis e entediantes.

Programas especiais devem ser criados para alunos talentosos cujas necessidades são ignoradas, enquanto professores e diretores lutam com a desordem crônica nas escolas.

Deve ser desenvolvida uma capacidade institucional para tratar desse problema, com o treinamento de especialistas em segurança escolar e a criação de ambientes alternativos de aprendizagem para alunos problemáticos que dificultam o ensino.

\section{Sindicatos}

Na América Latina, como em outras sociedades, os sindicatos dos professores freqüentemente se opõem às reformas do ensino, dizendo que são obras de tecnocratas de elite com objetivos não declarados de privatizar as escolas públicas, reduzir os custos e quebrar os sindicatos.

Os sindicatos latino-americanos marcaram a sua oposição às reformas com greves, manifestações de protesto, campanhas na mídia e o seu voto nas eleições.
Porém, no sistema federal do Brasil, os sindicatos de professores também são descentralizados, como os Estados e municípios. Alguns são geridos por burocratas de carreira, com pouco contato com os professores, o que não cria oportunidades de diálogo e negociação, com os líderes sindicais ou com a base de professores, sobre novos incentivos que não ameacem a perda de empregos.

A qualidade da liderança sindical varia entre as localidades, da mesma maneira que a liderança política de Estados e municípios. Em alguns lugares, especialmente no México, República Dominicana e Minas Gerais na década de 1990, como também em Nova York no período de 2003 a 2007, houve negociações bemsucedidas entre reformadores educacionais e os sindicatos de professores.

Escolas deterioradas significam condições de trabalho deterioradas. Assim, os sindicatos dos professores, fora do Brasil, gradativamente se engajaram na reforma escolar.

Alguns estão treinando e reciclando professores. Outros concordaram com os incentivos em função do desempenho. Em Nova York, Newark, Chicago, Boston, Baltimore, Miami e Minneapolis, os sindicatos aceitam a responsabilidade na administração das escolas públicas.

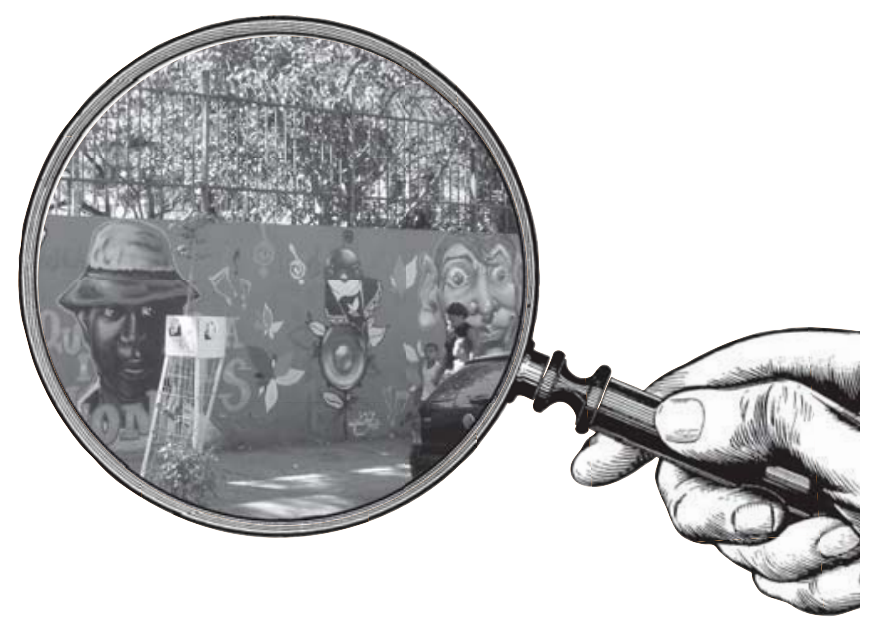


Em seu excelente livro Despite the Odds: The Contentious Politics of Education Reform, a professora Merilee Grindle, do Instituto de Estudos Latino-Americanos da Universidade Harvard, adverte que o futuro da reforma escolar é incerto "quando o apoio de professores é ignorado, quando sindicatos hostis continuam se opondo às mudanças e quando os incentivos para políticos, administradores, professores e pais acabam atuando contra as novas iniciativas". E acrescenta:

(...) as mudanças no sistema educacional precisam ser implementadas em nível de sala de aula, para aumentar o grau de aprendizado das crianças das habilidades e capacidades necessárias. Isso implica a necessidade de vários níveis de executores para que as novas iniciativas prosperem. Em algum ponto dessa longa cadeia de responsabilidades pelas tomadas de decisão, as atividades de reforma podem esmorecer, vítimas da inércia, da contenção política, dos julgamentos errados, das invejas entre organizações e dos emaranhados logísticos (...)

\section{É preciso coragem para adotar uma reforma escolar}

No início desta série de quatro artigos, perguntamos:

- Qual a relação entre ignorância e desordem social?

- Como operar uma sociedade complexa sem uma população instruída?

- Como serão nossas sociedades, daqui a dez ou 20 anos, se nossas crianças não conseguirem aprender? As autoridades de Nova York, numa atitude louvável, corajosamente decidiram enfrentar a realidade ameaçadora da desordem e do fracasso das suas escolas, respondendo com soluções criativas para corrigir as deformações na estrutura e incentivos do sistema.

Cometeram erros e se expuseram a uma intensa controvérsia política, porém seu trabalho já começa a mostrar resultados. Tanto as notas nas provas de leitura e matemática como os índices de graduação melhoraram, e a violência nas escolas diminuiu.

O secretário da Educação Joel Klein esteve em minha velha escola no Bronx, Evander Childs, para anunciar que

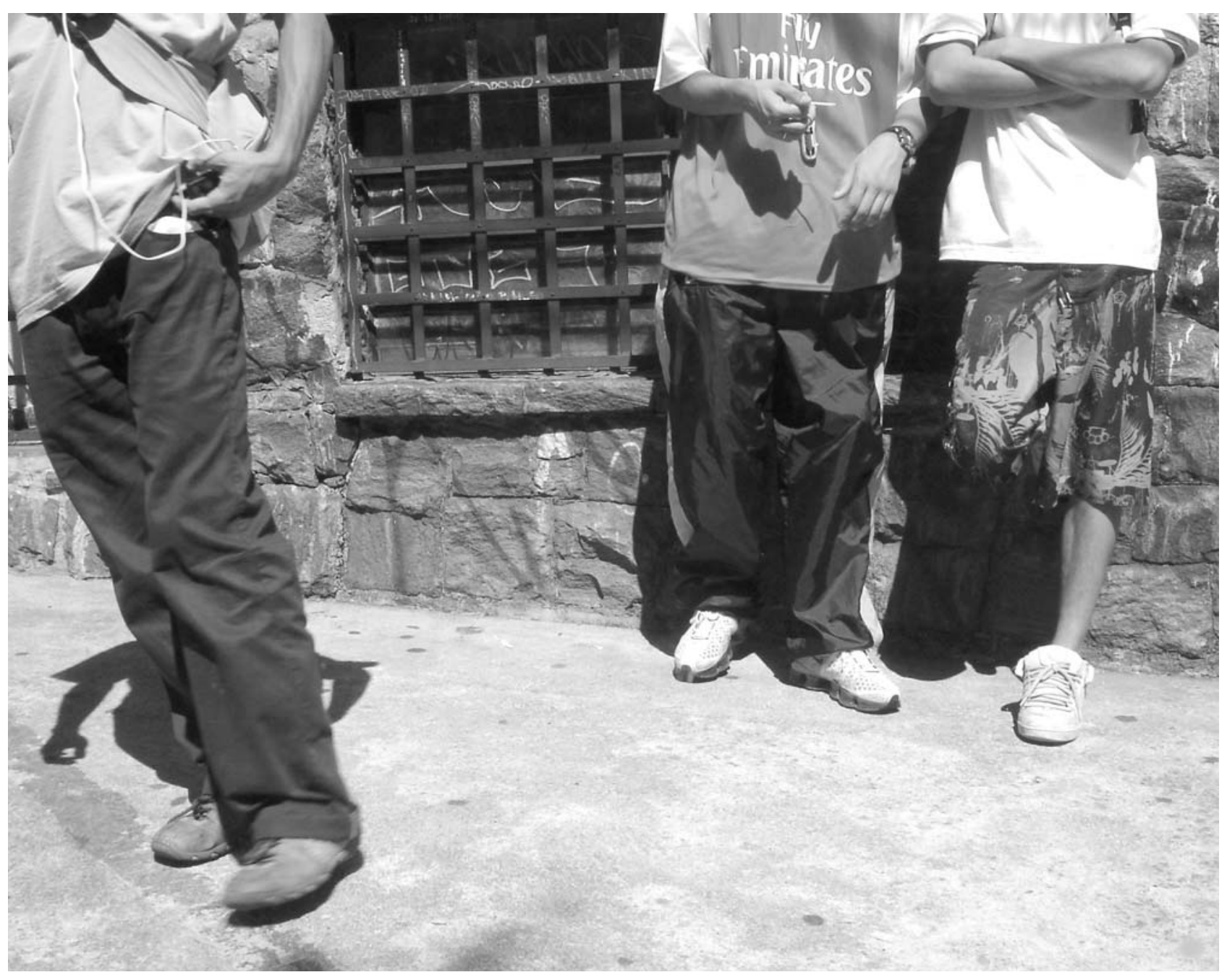


três pequenas escolas que funcionavam naquele prédio conturbado estavam formando $80 \%$ dos alunos do nível secundário, em comparação com os 31\% em 2002.

"As crianças precisam exercitar leitura, leitura, leitura”, disse Steven Chernigoff, diretor da Bronx High School for Writing and Communication Arts, escola superlotada, com 348 alunos, que ocupa um corredor no edifício da Evander Childs. E completa: "Grande parte da melhora se deve a um trabalho intensivo com os estudantes, individualmente ou em grupos pequenos. Estamos muito bem treinados na utilização de dados para acompanhar o progresso dos alunos a partir do momento em que entram em nossa escola. Explicamos a importância de eles se formarem no tempo certo. Se estão atrasados, oferecemos cursos de verão, aulas nos sábados e aulas individuais no fim da tarde."

A decisão de se iniciar uma reforma escolar em Nova York foi tomada por um homem, o prefeito Bloomberg, fazendo eco à inquietação geral, nos Estados Unidos, sobre as deficiências da educação pública.

Em São Paulo, a decisão também depende de um homem, o governador José Serra, que se formou em escolas públicas de São Paulo e no Instituto Politécnico, com doutorado em Economia pela Cornell University e que, exilado, trabalhou na Comissão Econômica para a América Latina - Cepal, das Nações Unidas, em Santiago do Chile, e, mais tarde, no Instituto para Estudo Avançado em Princeton, antes de se tornar secretário do Planejamento do Estado de São Paulo, ministro do Planejamento e, depois, da Saúde.

Estas credenciais impressionantes dão esperança para novas iniciativas, fazendo mais pela educação pública do que os governos passados.

Ser governador de São Paulo é missão repleta de problemas. Nos primeiros seis meses como governador, Serra concentrou seus esforços na obtenção de financiamento federal para o Rodoanel em torno da Grande São Paulo, para melhorar os trens suburbanos, prover infra-estrutura sanitária para loteamentos ilegais em torno do reservatório de Guarapiranga e para reparar as rodovias rurais deterioradas.

Em outras palavras, Serra focalizou o hardware do sistema, mais do que no software. 0 entanto, é o software que torna a sociedade produtiva.

No campo da educação, Serra concentrou-se em iniciativas isoladas, como a contratação de 4 mil estagi- ários para auxiliarem na alfabetização de crianças nas duas primeiras séries do curso primário.

Embora sejam medidas importantes, há necessidade de uma ação integrada para solucionar os problemas sistêmicos do ensino público, que sofreu terrivelmente por falta de ambição.

Como terá se sentido o governador Serra quando a Folha de S. Paulo, no mês passado, mostrou a deterioração da Escola Estadual Firmino de Proença, do bairro da Mooca, onde ele estudou, com os alunos perdendo quatro aulas em alguns dias da semana, por falta de professores?

"Nos dias de aula de ciências", disse um aluno, "passamos o tempo fazendo o jogo da velha".

\section{Nota}

1 “Reforma do ensino em São Paulo e no Brasil” Este é o último de quatro artigos sobre reforma escolar, publicados pelo jornal O Estado de S. Paulo, elaborados no Programa do Instituto Braudel Reforma do Ensino em São Paulo e no Brasil. O programa e os outros artigos podem ser acessados pelo site: 〈www.braudel.org.br.〉.

O Instituto Fernand Braudel está desenvolvendo um programa de pesquisas, debates e mobilização pública em prol da melhoria do ensino público em São Paulo e no Brasil. A partir de análises de experiências nacionais e internacionais bem-sucedidas, trabalha com gestores públicos, professores, políticos, empresários, pais e alunos para auxiliar no desenvolvimento de propostas de políticas e programas capazes de melhorar o ensino e o aprendizado na rede pública. O propósito do Instituto Fernand Braudel é somar esforços com lideranças que já demonstram interesse pela reforma do ensino.

Série de artigos sobre a reforma da educação

$1 \quad 0$ que deve ser feito?

Norman Gall, O Estado de S. Paulo, 15 de julho de 2007. Disponível em: 〈http://www.braudel.org.br/noticias/midia/pdf/estado_20070715.pdf〉

2 Ordem e desordem nas escolas

Norman Gall, O Estado de S. Paulo, 17 de junho de 2007. Disponível em 〈http://www.braudel.org.br/noticias/midia/pdf/estado_20070617.pdf〉

30 grande esforço de ensinar e aprender

- Patrícia M. Guedes, O Estado de S. Paulo, 20 de maio de 2007. Disponível em: 〈http://www.braudel.org.br/noticias/midia/pdf/estado_20070520. pdf>

4 A luta por melhores escolas em São Paulo e Nova York Norman Gall, O Estado de S. Paulo, 29 de abril de 2007. Disponível em: 〈http://www.braudel.org.br/noticias/midia/pdf/estado_20070429.pdf〉

5 Entrevista com o ministro da educação, Fernando Haddad.

Ele vai salvar a educação?. Época, 30 de abril de 2007. Disponível em: 〈http://www.braudel.org.br/noticias/midia/pdf/epoca_20070430.pdf〉 


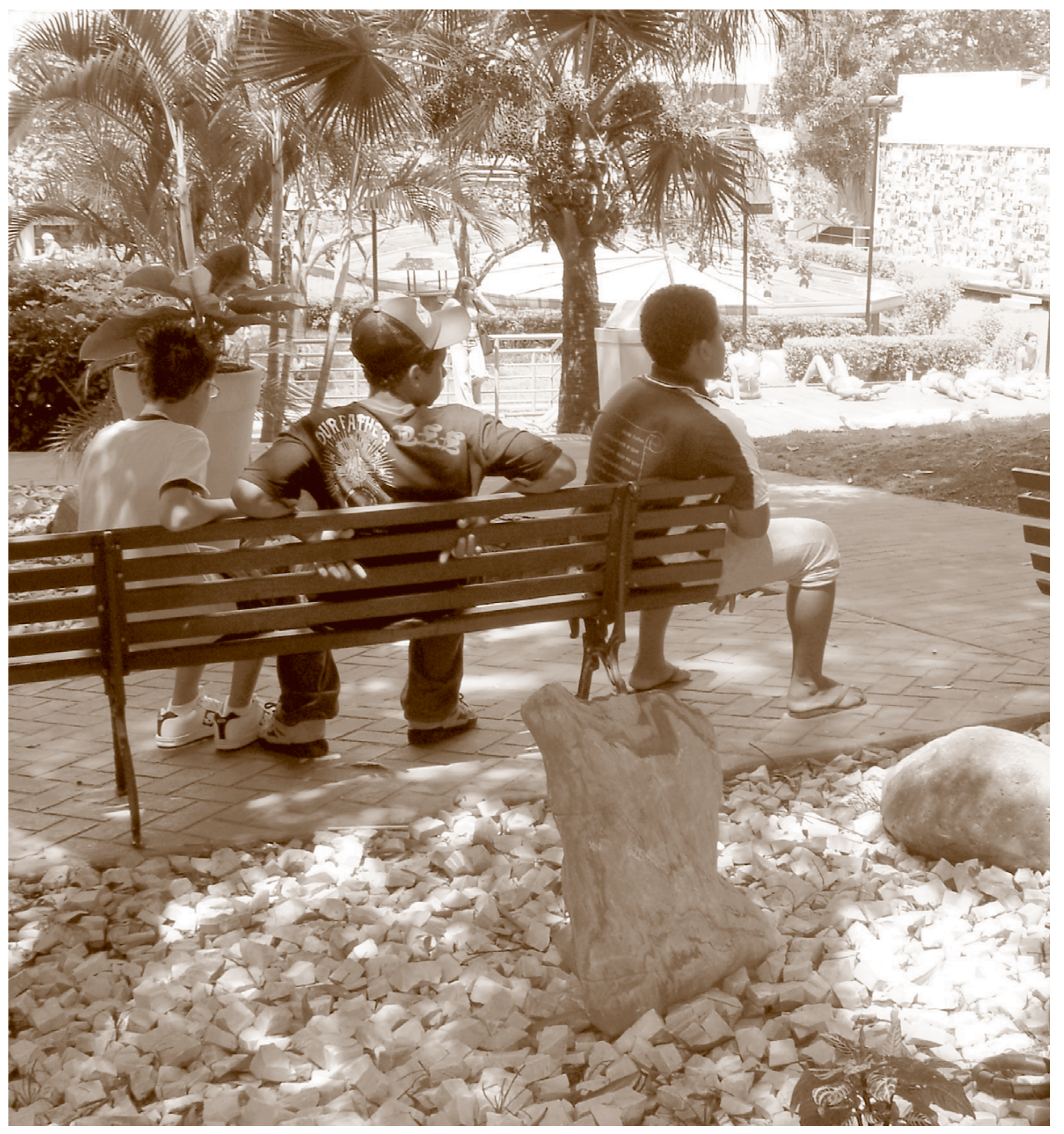

